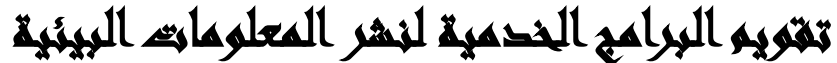

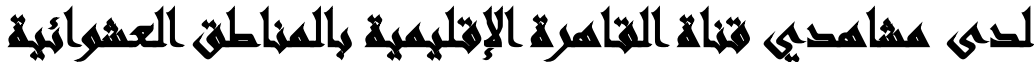

[11]

\section{نجلاء محروس محمود اسماعيل(')- سوزان يوسف القليني (ץ) - أسامة جبريل(؟)}

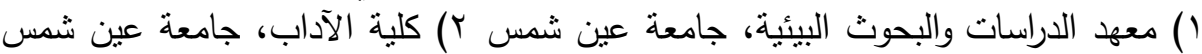
r) كلية التربية، جامعة عين شمس التروس

\section{المستمليv}

هدفت الدراسة إلى تقويم البرامج الخدمية لنشرالمعلومات البيئية لدى مشاهدى قناة القاهرة الإقليمية بالمناطق العشوائية بالقاهرة الكبرى نطاق إرسال القتاة.

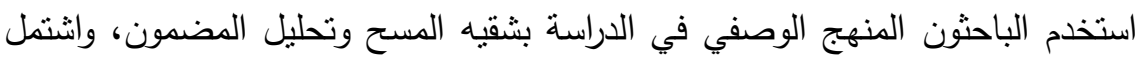

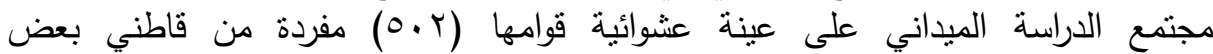
المجتمعات العشوائية بنطاق القاهرة الكبرى.

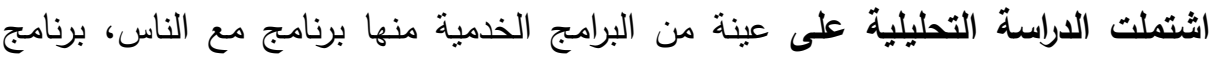

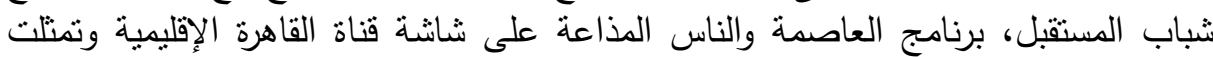
أدوات الدراسة في تصميم صحيفة استبيان واختبار للمعارف البيائية للاراسة الباسية الميدانية.

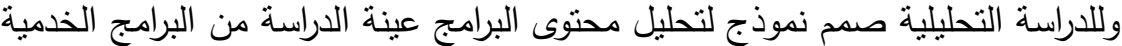
بقناة القاهرة الإقليمية. توصلت الاراسة إلى النتائج الأتية: وجود فروق معنوية بين المبحوثين عند مستوى معنوية

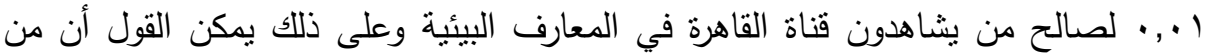

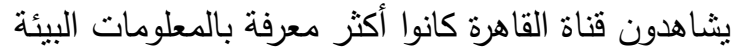

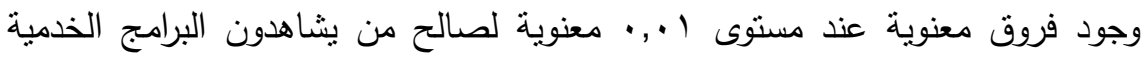

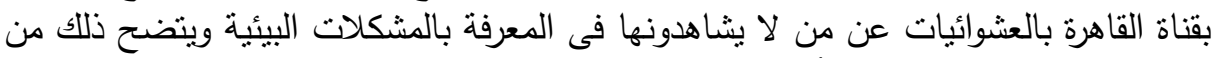

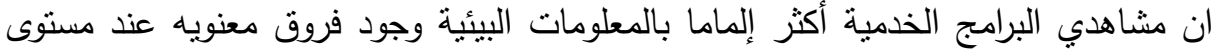

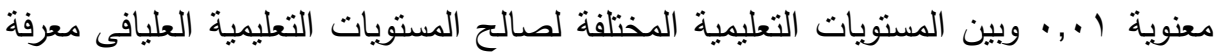
وتحديد المشكلات البيئية يفسر ذلك كلما زاد المستوى التعليمي لدى الفرد كلما زادئ مستوى التياتي

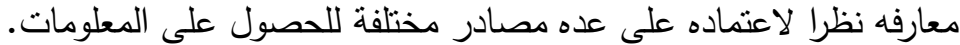
وجود فروق معنويه عند مستوى معنوية ال.,., فى المعارف البيائية بين المستويات

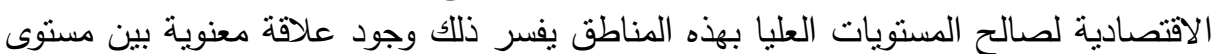

$$
\text { المجلد الخامس والأربعون، الجزء الأول، مارس } 9 \text { ب ب }
$$


المعلومات البيئية ومتغير المستوى الاقتصادي حيث كانت المستويات العليا اقتصاديا أكثر

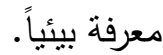

التوصيات

(1) إنثاء برامج بيئيه بقناة القاهرة الإقليمية حيث إن خريطة إرسالها تخلوا من البرامج البيئية

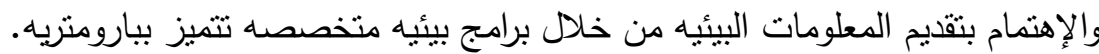

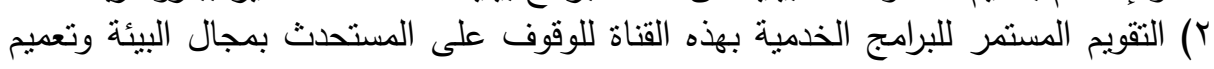

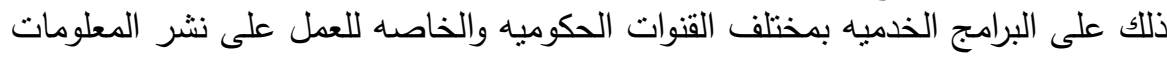
r) العمل على تدريب كوادر إعلاميه تهنم بشئون البيئة بالقطاع الإقليمي وتتعاون مع الأجهزه المعنيه بالبيئه. §) التعاون المستمر للحصول على المعلومات البيئية الموثقة من أجهزه شئون البيئة ومحطات

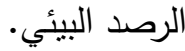

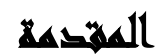

تحرص الحكومة على إتخاذ العديد من الإجراءات للحفاظ على البيئه من اجل توفير

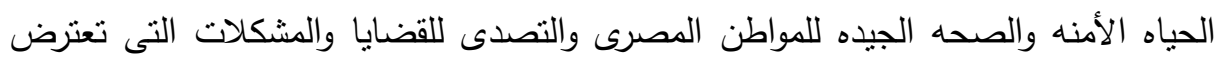

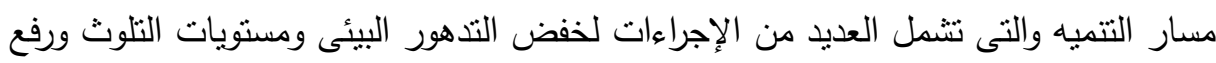
معدلات التتميه مع الحفاظ على البيئه والموارد الطبيعيه ولإِعلام دوره الرائد فى شحذ الطئ الطاقات والتوعيه والبناء الثقافى المجتمعى من خلال خطط إعلاميه هادفه تسعى لنشر المعلومات

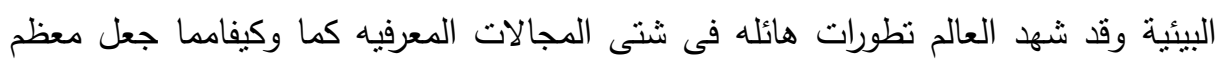
الدول تعمل على كيفيه إعداد أفرادها إعداد سليما وذلك بتزويدهم بمعارف ومهارات واتجاهات

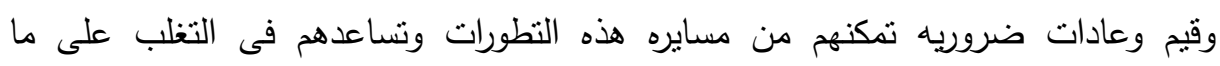
يواجهرم من مشكلات والتكيف مع بيئاتهم لمواجهة مطالب الحياة فقد تزايدت المشكلات البيئيه الحرجه التى اصبحت تهدد بإفساد وإنهاك موارد المقومات الآساسيه للحياة وبالتالى تهدد الإنسان في صحته وسبل معيشته،بل وفى إمكانيه بقاء جنسه على سطح الآرض. (محمد عبد

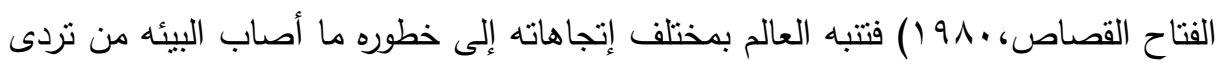

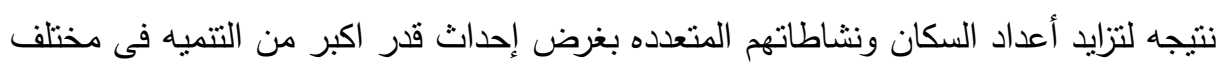

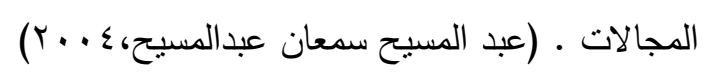


وقد تبين أن هناك حاجه ماسه وملحه لإعداد الإنسان المتقهم لبيئته والمدرك لظروفها والواعى بما يواجهها من مشكلات وما يهددها من أخطار والقادر على المساهمه الإيجابيه فى لئ لإنى

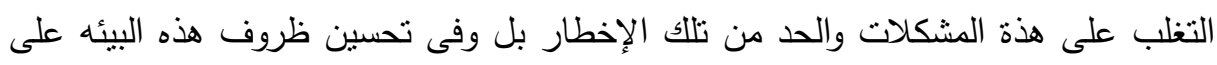

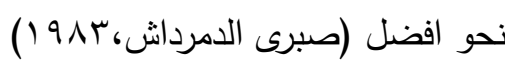
فنجد أنه مع المتغيرات المتلاحقه لتدهور البيئه وزياده اعدد السكان وانتشار العشوائيات وتدنى الوعى البيئى بمستحدثات التتميه بما يشكل خطوره على مستقبلنا ومستقبل الأجيال

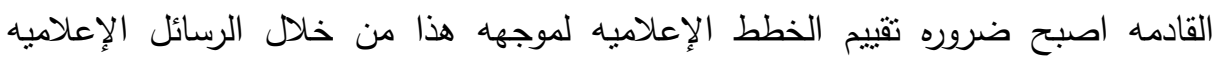

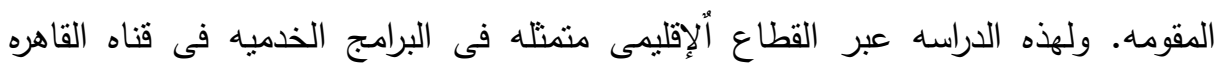

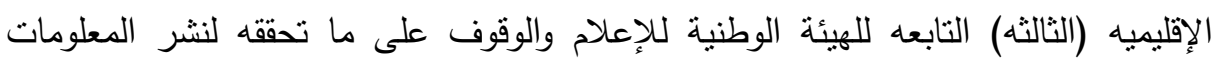

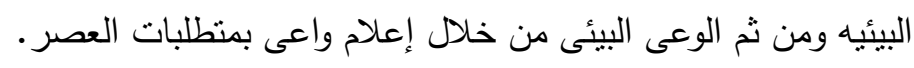

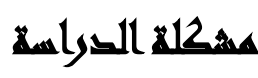

أظهرت الملاحظه عدم وجود اى برنامج متخصص فى مجال البيئه بقناه القاهرة علاوه

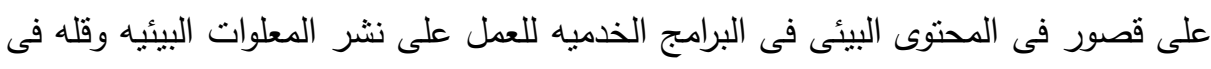
الوعى البيئى ببعض العشوائيات وبدراسه إستطلاعيه للباحثون علي عينه عشوائيه لبعض البه

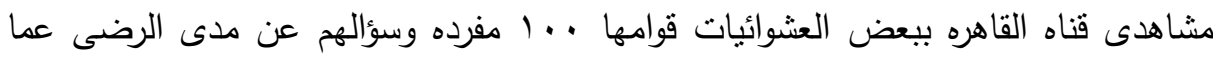

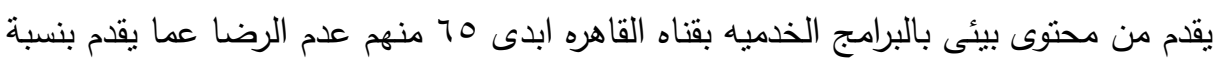

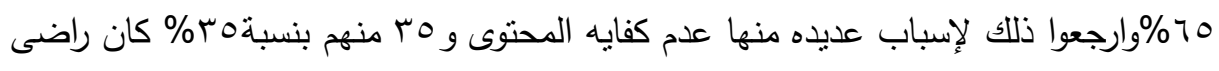

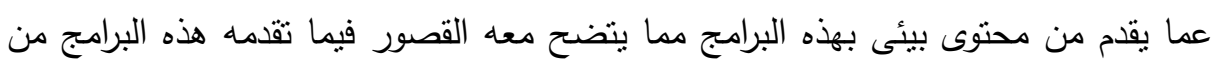

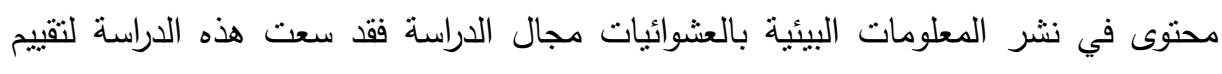

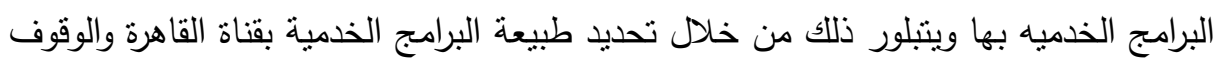
على جوانب القوة والضعف فيها وذللك بتحليل مضمونها لتحديد مناسبه وكفايه محتواها من المعلومات البيئية بما يحقق الوعى البيئى بنشر المعلومات البيئية . 


\section{توساولايت التوراسم}

تحددت مشكلة البحث في الاجابة على تساؤلات الدراسة وهى:

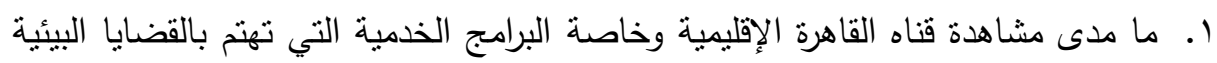

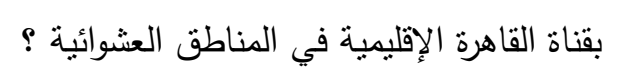

r. ما المضمون الذي يتضمنة البرامج الخدمية الخاص بالبيئة بقناة القاهرة الإقليمية لنشر

$$
\text { المعلومات البيئية؟ }
$$

r. ما التصور المقترح لنطوير البرامج الخدمية بقناة القاهرة الإقليمية لنشر المعلومات البيئية؟

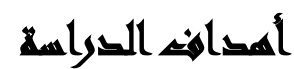

ا ـ التعرف على تأثنير قناة القاهرة الإقليمية فى المجتمعات العشوائية.

r. رصد حجم تعرض الجمهور لبعض البرامج الخدمية التي تهتم بالقضايا البيئية بالعشوائيات.

r. تحديد القضايا والمشكلات البيئية التى تتتاولها قناة القاهرة ببرامجها الخدمية وكيفيه طرحها

$$
\text { ومناسبتها. }
$$

ـ. الوقوف على مدى كفاية المحتوى والزمن المخصص للقضايا البيئية بهذه البرامج.

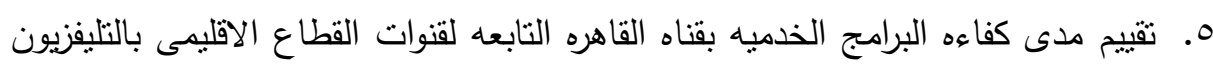

$$
\text { المصرى لنشر المعلومات البيئية }
$$

\section{هغوض الدواسة}

$$
\text { يحاول البحث التحقى من صحه الفروض الآتيه }
$$

ا.توجد علاقه ذات دلاله إحصائيا بين التعرض لقناة القاهرة الإقليمية وبين المعرفة البيئية. r.توجد علاقه ذات دلاله إحصائيا بين التعرض للبرامج الخدمية بقناة القاهرة الإقليمية

$$
\text { والمعرفة بالمشكلات البيئية . }
$$

r.وجدعلاقه داله إحصائيا بين المشاهدين في مستوى المعرفة وتحديد المشكلات البيئية

$$
\text { بناءعلى المستوى التعليمى. }
$$


ع .توجدعلاقه داله إحصائيا بين المشاهدين في مستوى المعارف البيئية بناء على المستوى

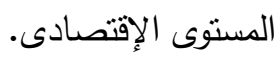

\section{مبوكالفواسم}

يلتزم البحث بالحدود التالية:

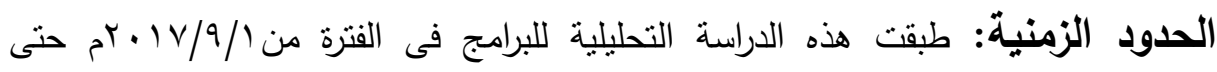

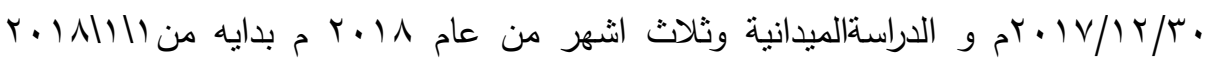

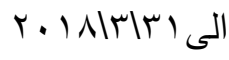

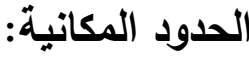

- للاراسة التحليلية: عينه من البرامج الخدميه بقناه القاهرة الخدمية : ( مع الناس- شباب المستقبل - العاصمة والناس)

- للاراسة الميدانية: تتمنل ببعض المناطق العشوائية بنطاق القاهرة الكبرى فتمنلت: محافظه القاهرة: بمنطقه منشأه ناصر - بولاق ابو العلا - عزبه خير الهه البساتين ومحافظه الجيزة: إمبابة- بولاق الدكرور - أبو النمرس ومحافظه القليوبية: قليوب البلد- المرج - شبرا الخيمة.

الحدود البشريةة: تتمثل بعينه عشوائية بسيطة غير احتماليه للجمهور بالمناطق العشوائية السابقة قوامها r م م مفرده.

\section{منهمج القراسلة}

استخدم الباحثون المنهج المستح بثقيه : المسح الميدانى: وذلك بالدراسة الميدانية لعينة عشوائية بسيطة من الجمهور نطاق القاهرة الكبرى ببعض المناطق العشوائية

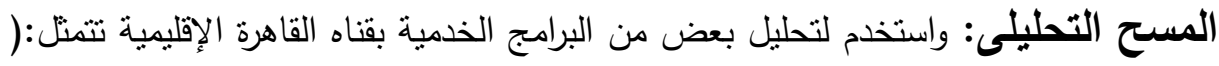

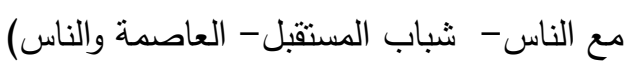

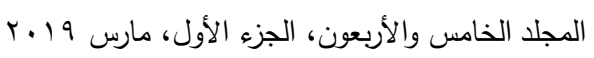




\section{أهمية القواسمة}

تتمثل أهية البحث في جانبين هما الجانب النظرى والجانب التطبيقى كما يلي:

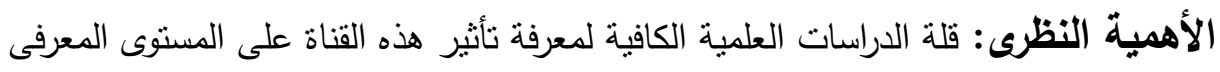

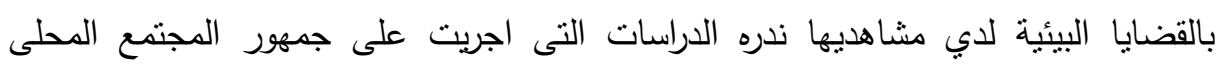

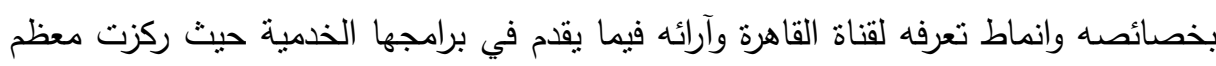
الدراسات على دراسة القنوات المركزية دون الاهتمام الكافى بهذه القناة. دراسة منطلبات الجمهور وتطلعاته وربط ذلك بمحتوي المقدم بالبرامج الخدمية للقناة. الاهمية التطبيقي: دراسة تأثير قناة القاهرة من خلال برامجها الخدمية على الوعي البئئي للمجتمع المحلى وخاصة جمهورها من العشوائيات.

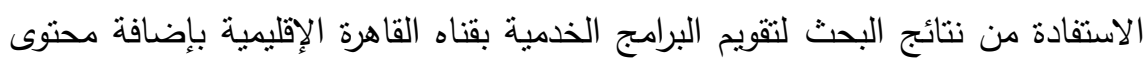

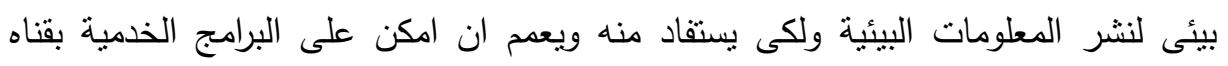
القاهرة - الق

\section{كمسلحاهي التراسها}

1. التقويم: بأنه عمليه منهجيه تقوم على أسس علميه تستهدف إصدار الحكم على مدخلات

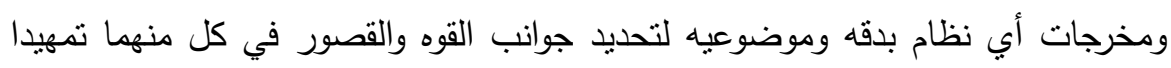

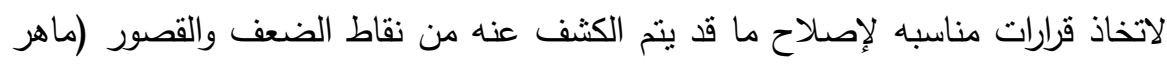

$$
\text { إسماعيل صبري ومحب كامل الرافعى، ب. . r). }
$$

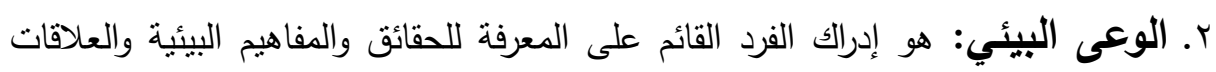

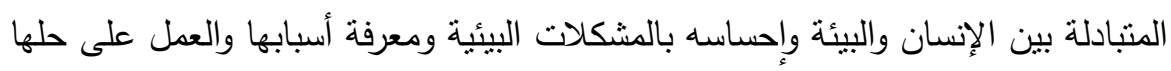

$$
\text { والحد من ظهورها مرة أخرى. ( محمد محمود العجوز ، ـ99 (1). }
$$

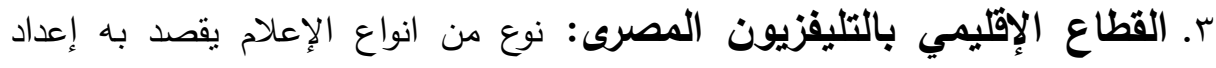

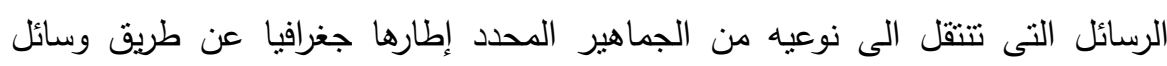

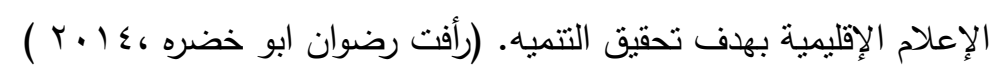

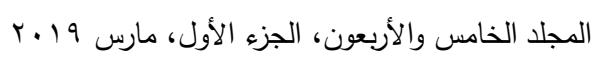


ء. البرنامـج الخدمى:هى التى تقدم الخدمات الإعلاميه المرئيه لتحقيق اهداف التتميه بجميع ابعادها بما يحقق الوعى وتتميه الإتجاهات وغرس القيم نحو قضايا معينه تخدم

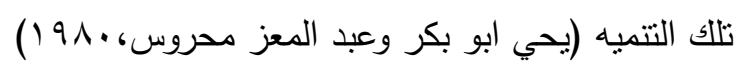

ه. المناطق العشوائية: هى المناطق التى تضم مجموعات بشريه تقطن بمناطق بين القرى والمدن فرضنها طبيعة أعمالهم واحتياجاتهم المعيشية ويتسم بأنهم من الفئات الدنيا

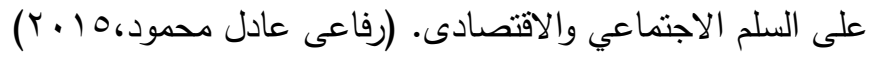

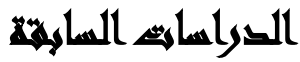

$$
\text { المحور الأول: التليفزيون والبيئة }
$$

بعنوان: " فاعلية تصور مقترح بإذاعة الثباب والرياضة لتنمية بعض أبعاد المسؤلية البيئية

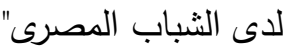
هدفت الاربسة:

1-التعرف فاعلية تصور مقترح عن البيئية فى تتمية المسؤلية البيئيه لدى الثباب المصرى r- غرس مفهوم المسؤلية البيئيه أهم نتائج الاراسة: 1- أظهرت النتائج فاعلية البرنامج المقترح حيث راعى الأسلوب الجيد فى عرض البرنامج

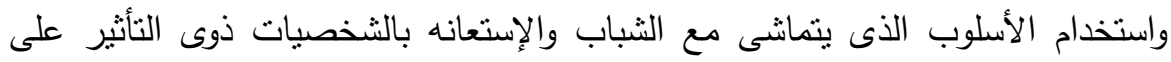

$$
\text { الثباب والمضمون الملائم. }
$$

التوصيات: استخدام أطر إخباريه غير التى تقدم فى برامج الإذاعة مع إعاده تتظيم المحتوى للخبر البيئى ووضعه فى إطار إهتمامات الثباب.

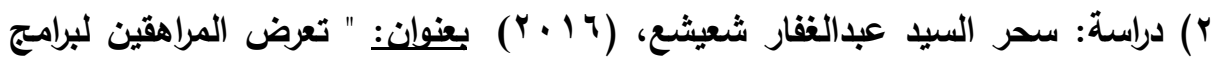
السياحة البيئية فى التليفزيون المصرى وعلاقتها بتثكيل وعى المراهقين نحوها " هدفت الاراسة: 
1-التعرف على دور البرامج السياحه البيئيه فى تشكيل وعى المراهقين بما هيه السياحه

$$
\text { البيئيه. }
$$

r-توضيح العلاقه بين التعرض لبرامج السياحه البيئيه فى التليفزيون وتتشكيل وعى المراهقين

$$
\text { متمثنلا فى سلوكياتهم نحو البيئه. }
$$

أهم نتائج الدراسية:

1- وجود علاقه داله إحصائيا بين تعرض المراهقين لبرامج السياحه البيئيه ودرجة الوعى بما هيا السياحه البيئيه.

r- وجود علاقه داله إحصائيا بين تعرض المراهقين لبرامج السياحه البيئيه ودرجة الوعى لهي بسلوكياتهم نحو البيئه

التوصبات:

ا-ضرورة التجديد فى شكل ومضمون برامج السياحه البيئيه فى التليفزيون المصرى والبعد عن النمطيه

r-اختيار مواعيد إذاعه مناسبة للموضوع والجمهور المستهدف

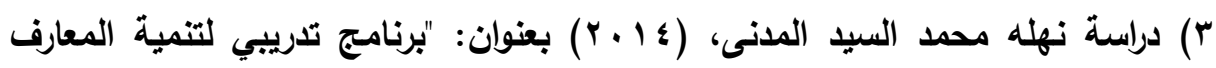

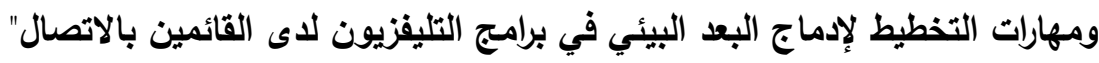

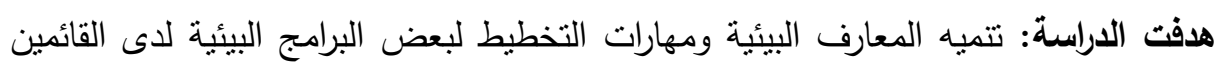
بالاتصال وتتاولت الدراسة إعداد قائمه بأهم القضايا البيئية الملحة.

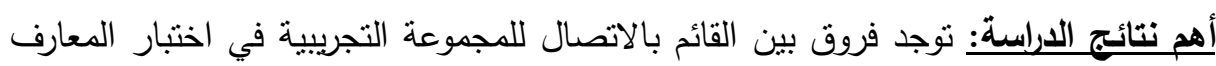
قبل وبعد تطبيق البرنامج لصالح تطبيق البرنامج. التوصبات تطبيق البرنامج التدريبي على القائمين بالاتصال بالقنوات التليفزيونية القومية والخاصة المحور الثاني : دراسات اهتمت بالإعلام و العشوائيات

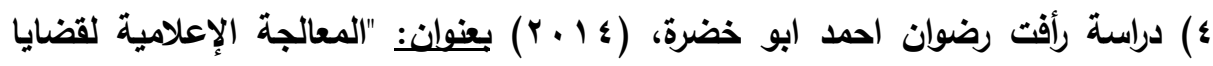

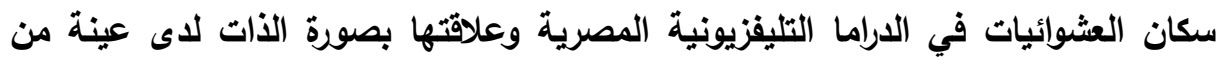

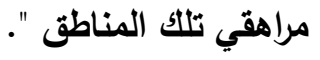


هدفت الدراسة: رصد العلاقة بين الدراما المصرية لقضايا العشوائيات وصوره الذات لدى عينه من مراهقي تلألك المناطق

أهم نتائج الدراسة: توجد علاقه ارتباطيه ودلاله إحصائيه بين مشاهده المراهقين للدراما التى تتتاول سكان العشوائيات وتكوين صوره الذات لايهم: نوجد علاقه إرتباطيه ودلاله إحصائيه بين كثافه مشاهده المراهقين للاراما التى تتتاول سكان العشوائيات وتكوين صوره الذات لديهر التتصبات: الإهنمام بالمحتوى المقدم بالدرامى لتحقيق صوره افضل للأات لدى مراهقى نللك

المناطق

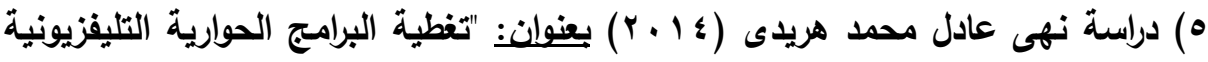
المصرية لقضايا المهشين وادراك الجمهور لها" قد استخدمت المنهج الوصفى، واعتمدت على عينه عشوائية من جمهور المشاهدين · Vـ بلغت مبحوث بتحليل مضمون إ احلقه من اربع برامج حوارية.

هافت الدراسة: تحديد ملامح تغطيه البرامج الحوارية التليفزيونية المصرية لقضايا الفئات المهشة وتحديد حجم التغطية والكثف عن معتقدات وافكار الجمهور المصرى حول قضايا

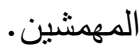
أهم النتائج: ضعف نتاول البرامج الحوارية لقضايا المهمشين، عدم وجود علاقه بين مدى

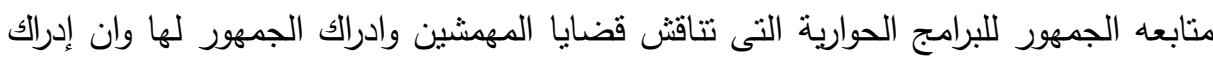

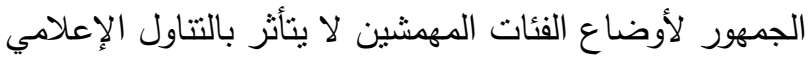

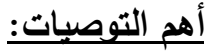
( ) التزام البرامج الحوارينبالموضوعية في تتاولها لقضايا المهمشين.

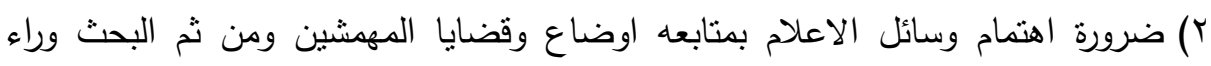
اسباب ظهورها

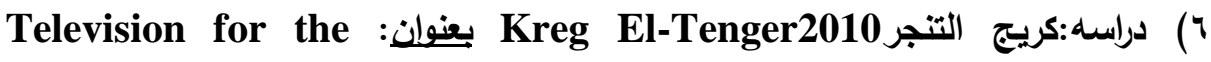
Environmentinindia Development communication نشر المعلومات البيئيه وتنميه الوعى البيئ فى الهند.

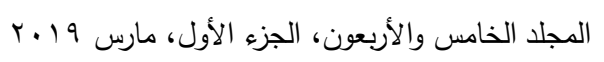




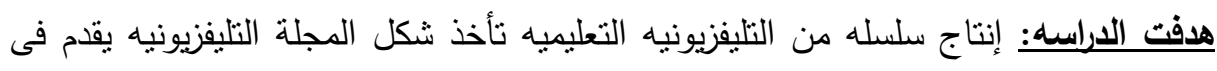

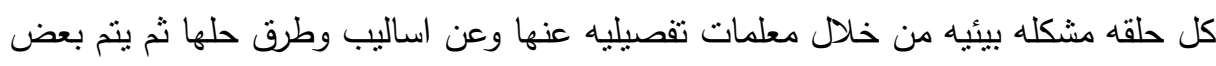
العرض المناقثة لتحديد الإنتفاده منها وإلى اى مدى استفاد المشاهد من المضمون البهائي المقدم النتائج: اثتت التجربه تفوق التليفزيون فى نشر الوعى البيئى وزيادة المعلومات البيئيه عن مشكلات الييئه وقضاياها.

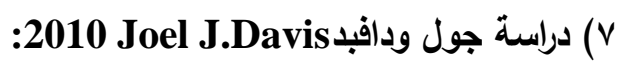
The Effects of massage framing on Response of Environmental communication الإتجاهات والسلوكيات البيئيه المسؤله هدفت الدراسه: تأثير شكل وطريقه صياغه الإعلام البيئى على الإتجاهات والسلوكيات البيئيه

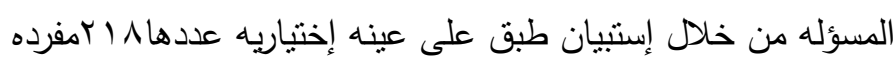

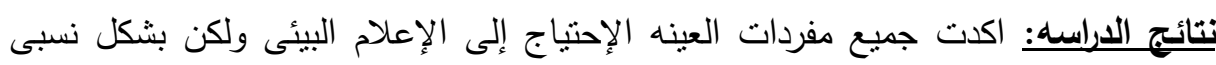

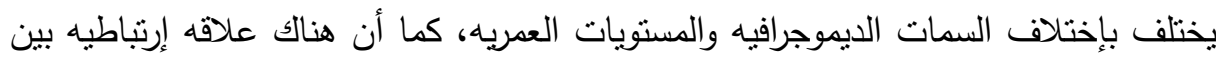

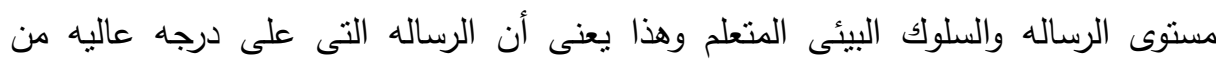

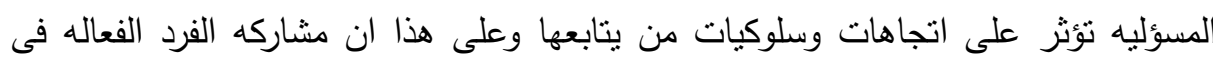
السلوك البيئى يمكن ان يعززمن خلال وسائل الإعلام.

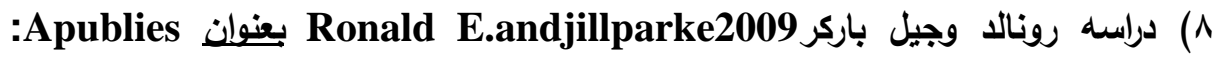
Environmental information sources and: Evalution of massmedia

$$
\text { دور الإعلام كمصدر للمعلومات البيئيه لاى الجمهور }
$$

هلفت الدراسه: التعرف على دور الإعلام كمصدر للمعلومات البيئيه من خلال إعداد إسنتيان

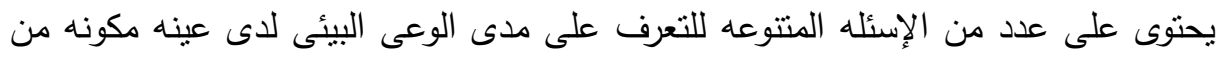
بابr مفرده من خلال الكقابله الثخصيه معهم.

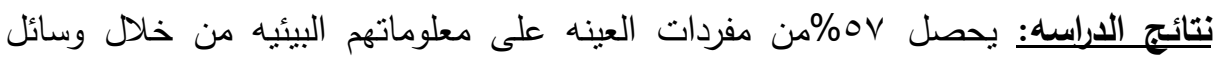
الإعلام فى حين ذكر r؟٪ من مفردات العينه بإنهم لا يعتدوا على وسائل الإعلام وهناك

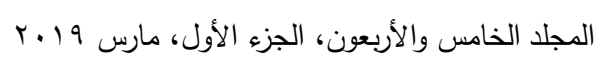


فروق داله إحصائيا لا بين مدى متابعه المعلومات وجاءت هذه الفروق فى صالح من هم اكثر

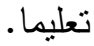

\section{الإطالر المظظرى}

نظرية الغرس الثقافى: ترتكز الدراسة على نظرية الغرس الثقافى وهى تعتمد علي عدة

دعائم أساسية تتمنل في: أ. التليفزيون وسيلة فريدة للغرس: يعمل التليفزيون نافذة أو انعكاسًا للعالم ولكنه عالم في

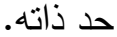

ب.رسائل التليفزيون تكون نظامًا متماسكًا يعبر عن الاتجاه السائد: حيث يشاهد كثيرو

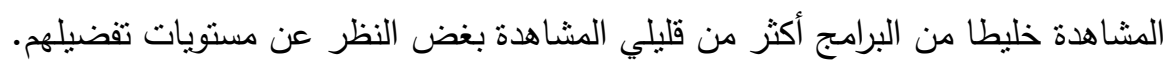
ج. مضمون رسائل التليفزيون يقدم دليلاً علي عملية الغرس: حيث تعد الرسائل الإعلامي بطرق تؤدى بفاعليه لنشر المعلومات

الإعلام البيئى: مجموعه الرسائل الإعلاميه المحدده الإهداف التى تستهدف تتميه المجتمع فى محاوله لإإدرالك الفرد القائم على المعرفة للحقائق والمفاهيم البيئية والعلاقات المنبادلة بين

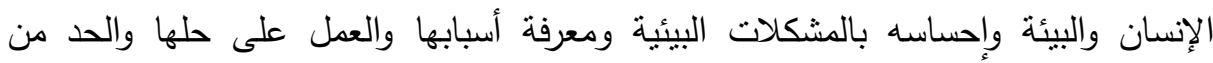
ظهورها مرة أخرى.اهد(فه: نشر المعلومات والمعارف البيئيه القطاع الإقليمي بالتليفزيون المصرى: مفهومه يقصد به إعداد الرسائل الإعلاميه التى تتنقل الى نوعيه من الجماهير المحدد إطارها جغرافيا عن طريق وسائل الإعلام الإقليمية

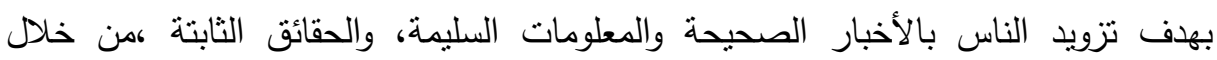
عرض فنى يساعد الناس علي تكوين رأى صائب في واقعه من الوقائع بحيث يعبر هذا الرأي تعبيرا موضوعيا عن عقليه هذه الجماهير وميولهم. المناطق العثوائية: تعريفها:هى المناطق الغير مخططه والغير منظمه و التى تم البناء بها بطرق عشوائيه وتضم مجموعات بشريه تقطن بهاوقد تكون بين القرى والمدن فرضتها

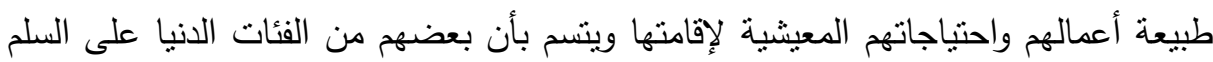

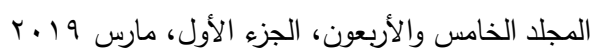


الاجتماعي والإقتصادى نشأتها: يؤرخ الباحثون بإن بدأ ت بظهور منطقه عزبه الصعايده

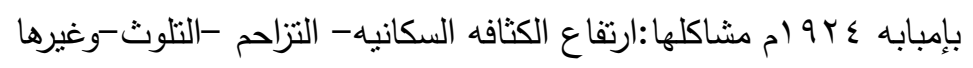
التقويم: تعريفه: عمليه منهجيه نقوم على اسس علميه تستهدف إصدار الحكم على ملى مدخلات ومخرجات أي نظام بدقه وموضوعيه لتحديد جوانب القوه والقصور في كل منهما

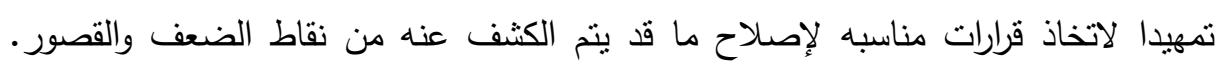

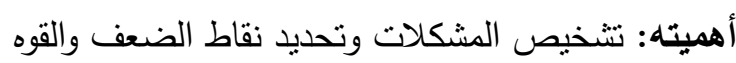

\section{إجراءاهي التوراسلا}

ترتكز اجراءات الدراسة على التعرف على فاعلية البرامج الخدميه بقناه القاهره لنشر

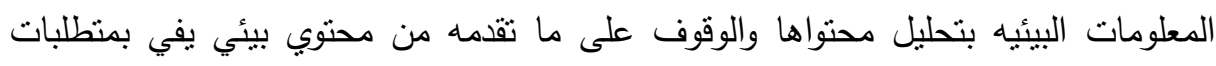

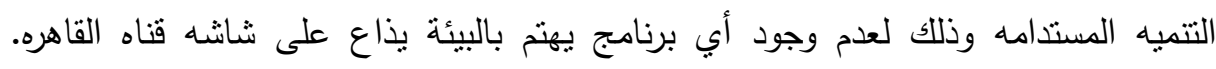

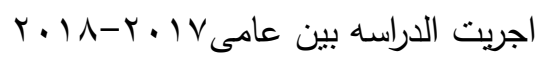

وقد استخدم الباحثون المنهج الوصفي بثقيه المسح وتحليل المضدون.

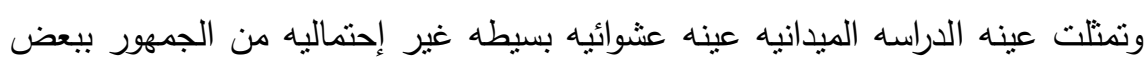

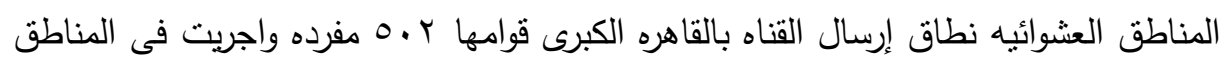

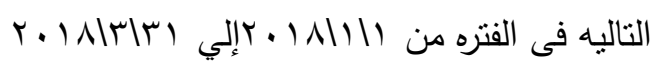
محافظه القاهره ( منشأه ناصر مبولاق ابو العلا -عزبه خبر اله )

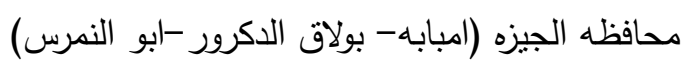

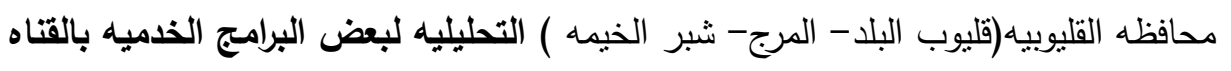

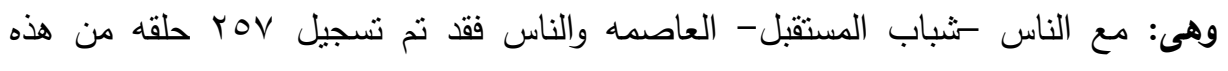

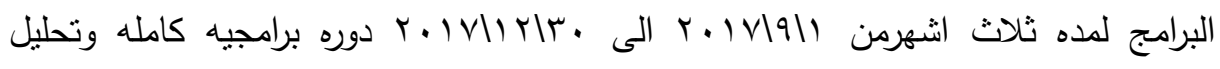

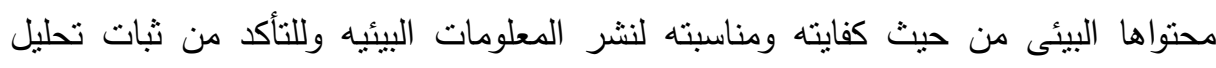

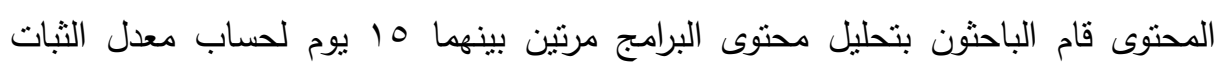

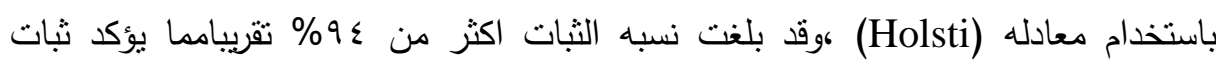
التحليل . بانسخ 


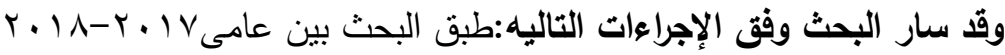

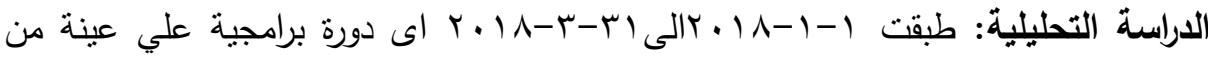
البرامج الخدمية وهى:مع الناس(فترة الظهيرة) و شباب المستقبل(فترة الوسط) و العاصمة والناس( فترة المساء ) التى تذاع على قناة القاهرة ا.صمم الباحثون قائمة بالمعلومات البيئية التى يجب ان يحتويها مضمون البرامج الخدمية للوقوف على المحتوى المناسب للمعلومات البيئية التى يجب ان بتضمنهالبرنامج الخدمى بقناة القاهرة ليعمل على نشر المعلومات البيئية والتى قد تكون مؤشر للمعارف البيئية للجمهور ووضعت وفق اراء وتعديلات السادة المحكمين r. صمم الباحثون صحيفة تحليل محتوى هذة البرامج وطبقت بعد إجراءات الصدق المحكمين

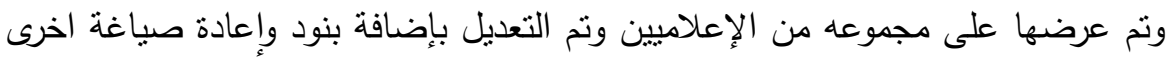
وفق اراء وتعديلات الساده المحكمين ونم حساب الثبات بإعادة التحليل بفاصل زمنى 10 يوم ويرتكز ابعادها على ورود وعدد وزمن وطريقة التتاول وضيوف الفقرات البيئية بها.

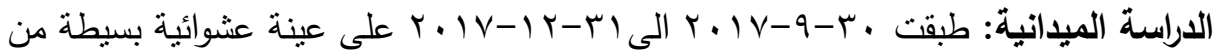
قاطني بعض المناطق العشوائية نطاق إرسال القناة وهم ب .0 مفردة من ثلاث محافظات هى القاهرة-الجيزة- القليوبية وهى نطاق ارسال قناة القاهرة(الثالثة) r.صمم الباحثون إختبار معلومات بيئية يحتوى على / سؤلاً وتم تطبيقة بعد التحقق من صدقه عن طريق صدق المحكمين حيث تم عرضه فى صورته الاوليه علي مجموعه من الساده المحكمين وبناء علي تعليماتهم تم صباغة بعض المفردات وحذف غير المناسب و ايضا التحقق من الصدق الذاتى وتم تطبيقه وفق اراء السادة المحكمين ولإجراءات التبات استخدم الباحثن طريقه إعادة التطبيق للإختبارعلي عينه إستطلاعية قوامها لـ مفردة بفاصل زمنى 10 يوم وفق اراء السادة المحكمين ويرتكز ابعاده على الجانب المعرفى من معرفة وتحديد والإحساس بالمشكلات البيئية وطبق على مجموعة البحث

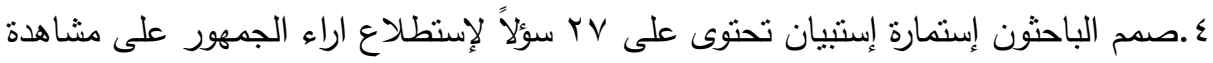
قناة القاهرة وبرامجها الخدمية ومدى رضاهم عما يقدم من محتوى بيئى وتحقق الباحثون

$$
\text { المجلد الخامس والأربعون، الجزء الأول، مارس } 19
$$


من صدق إستمارة الإستبيان عن طريق صدق المحكمين وذللك بعرضها علي مجموعه من

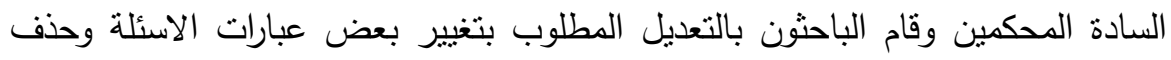

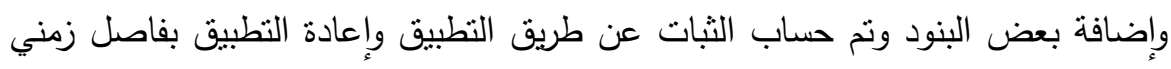
10 يوم على عينة إستطلاعية قوامها ل. .1 مفردة وطبق الباحثون هذة الادوات من الاختبار و الإستنيان لمعرفة والوقوف على المعارف البيئية لهم . وفيما يلى توضيح للإجابة على أسئلة الدراسة:

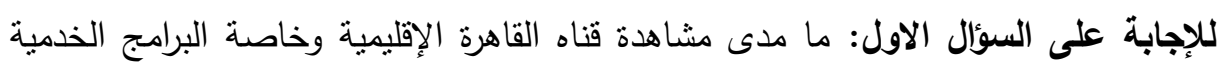

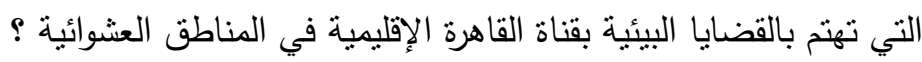
تم إتباع الآتي: إعداد صحيفه استبيان لآراء الجمهور في بعض المناطيان العيد العشوائية وعرضها على عدد من الساده المحكمين لإجراء التعديلات اللازمة وذللك للوصول للصورة اللهاء النهائية. للإجابة عن السؤال الثانى: ما المضمون الذي يحتويه البرامج الخدمية الخاص بالبيئة بقناة القاهرة الإقليمية لنشر المعلومات البيئية؟ تم إتباع الآتي: تحليل مضمون بعض البرامج الخدمية وذللك بتصميم صحيفه لتحليل محتوى لما تتضمنه هذه البرامج من محتوى بيئى وتقييمه وعرضها على عدد من الساده المحكمين للإجابة على السؤال الثالث: ما التصور المقترح لتطوير البرامج الخدمية بقناة القاهرة الإقليمية

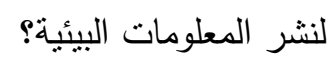

تم إتباع الآتي: تقديم مقترح بعد تصميم قائمة بالمعلومات البيئية و إختبار معلومات البيئية

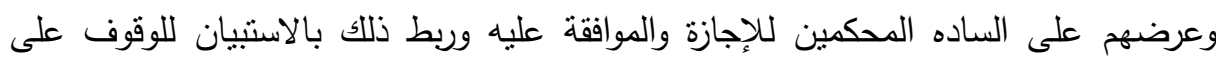
تأثير المحتوى البيئي بهذه البرامج على من يشاهدونها ونم إستخدام المعاملات الإحصائية لإيجاد علاقات بين هذة البيانات وبناء علي رصد النتائج م نم مناقتشتها وتفسيرها.

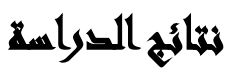

1 التحليلية لثلاث برامج خدميه توضح القصورفى التتاول البيئى بهذه البرامج جدول(1) يوضح أسلوب طرح القضية|البيئية

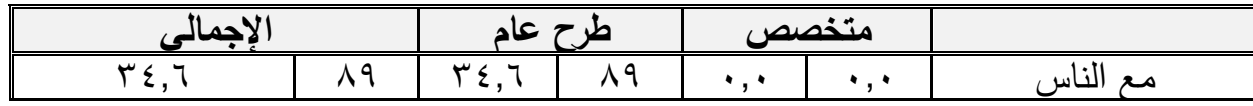

$$
\text { المجلد الخامس والأربعون، الجزء الأول، مارس } 9 \text { 1 ـ ب }
$$


مجلة العلوم البيئية

معهد الدراسات والبحوث البيئية - جامعة عين شمس لئ

\begin{tabular}{|c|c|c|c|c|c|c|}
\hline rr,q & $\Lambda \vee$ & rr,q & $\Lambda V$ & $\cdot, \cdot$ & $\bullet, \cdot$ & العاصمة والناس \\
\hline T, & $\wedge 1$ & $r 1,0$ & $\lambda I$ & $\cdot, \cdot$ & $\cdot, \cdot$ & شباب المستقبل \\
\hline $1 \cdots$ & rov & $1 \cdots$ & rov & $\cdot, \cdot$ & $\cdot, \cdot$ & الإجمالي \\
\hline
\end{tabular}

• طرح القضية يتمثل في الطرح العام وليس طرح متخصص

جدول(ץ): يوضح أسلوب مناقتشة القضايا البيئية

\begin{tabular}{|c|c|c|c|c|c|c|c|c|}
\hline \multicolumn{2}{|c|}{ الإجمالى } & \multicolumn{2}{|c|}{ متعمق } & \multicolumn{2}{|c|}{ متوسط العمق } & \multicolumn{2}{|c|}{ سطىى } & \\
\hline$r \varepsilon, 7$ & 19 & $\cdot, \cdot$ & $\cdot, \cdot$ & $\mathrm{V}, \varepsilon$ & 19 & $Y V, Y$ & $V$. & مع الناس \\
\hline rr, & $\lambda V$ & $\cdot, \cdot$ & ${ }^{\circ},{ }^{\circ}$ & $\cdot, \cdot$ & ${ }^{\circ}$ & $r r, q$ & $\Lambda V$ & العاصمة والناس \\
\hline$M 1,0$ & $\Lambda 1$ & $\cdot, \cdot$ & $\cdot, \cdot$ & $r, 1$ & $\Lambda$ & $r \wedge, \varepsilon$ & $V T$ & شباب المستقبل \\
\hline $1 \ldots$ & rov & $\cdot, \cdot$ & $\cdot, \cdot$ & $1 \cdot, 0$ & TV & 19,0 & rT. & الإجمالي \\
\hline
\end{tabular}

• غلبت السطحية على مناقشه القضايا البيئيه 
جدول(r): يوضح ضيوف الفقرات البيئية

\begin{tabular}{|c|c|c|c|c|c|c|c|c|}
\hline \multicolumn{2}{|c|}{ الإجمالي } & \multicolumn{2}{|c|}{ خبيز } & \multicolumn{2}{|c|}{ مسئول } & \multicolumn{2}{|c|}{ |تصال تليفوني } & \\
\hline$r \varepsilon, 7$ & 19 & $9, r$ & TE & YO,r & 70 & $\cdot, \cdot$ & . & مع الناس \\
\hline$r r, q$ & $\Lambda V$ & $\cdot, \cdot$ & - & $r \mu, q$ & AV & $\cdot, \cdot$ & . & العاصمة والناس \\
\hline$\Gamma, 0$ & $\Lambda 1$ & $\cdot, \cdot$ & - & $\cdot, \cdot$ & - & $\Gamma, 0$ & $\Lambda 1$ & شباب المستقبل \\
\hline $1 \cdots$ & TOV & $9, r$ & $T \xi$ & $09, Y$ & $10 Y$ & $\Gamma, 0$ & $\Lambda 1$ & الإجمالي \\
\hline
\end{tabular}

• ق قلة الاستعانة بخبير متخصص فى مجال البيئة

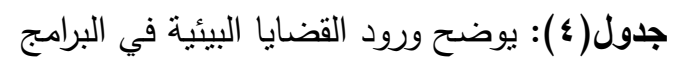

\begin{tabular}{|c|c|c|c|c|c|c|}
\hline \multicolumn{2}{|c|}{ الإجمالى } & \multicolumn{2}{|c|}{$\bar{y}$} & \multicolumn{2}{|c|}{ نعم } & \\
\hline$r \varepsilon, 7$ & 199 & $\Gamma, 1$ & A. & $r, 0$ & 9 & مع الناس \\
\hline$r \mu, q$ & AV & Yq,Y & Vo & $\varepsilon, V$ & IT & العاصمة والناس \\
\hline$\Gamma 1,0$ & $\Lambda_{1}$ & $\Gamma \wedge, \wedge$ & $V \varepsilon$ & $Y, V$ & $\bar{v}$ & شباب المستقبل \\
\hline$\ldots$ & TOV & $\wedge 9,1$ & rrq & $1 \cdot, 9$ & rA & الإجمالى \\
\hline
\end{tabular}

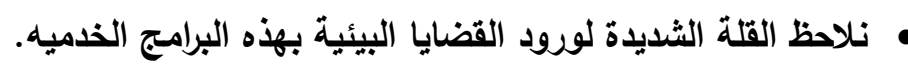

جدول(0): يوضح زمن ورود القضايا البيئية في البرامج

\begin{tabular}{|c|c|c|c|c|c|c|c|c|}
\hline \multicolumn{2}{|c|}{ الإجمالي } & \multicolumn{2}{|c|}{ شباب المستقبل } & \multicolumn{2}{|c|}{ العاصمة } & \multicolumn{2}{|c|}{ مع الناس } & \\
\hline$\Lambda 0, V$ & $T \Sigma$ & $r o,$. & $\bar{v}$ & $\varepsilon r, q$ & $T M$ & $1 V, 9$ & 0 & اقل من هدقائق \\
\hline $\mathrm{v}, 1$ & $r$ & . & . & . & . & $\mathrm{v}, 1$ & $r$ & من 0- م دقائق \\
\hline $\mathrm{v}, 1$ & $r$ & . & . & . & . & $\mathrm{v}, 1$ & $r$ & من • (- . r دقيقة \\
\hline $1 \cdots$ & YA & ro, & $\mathrm{v}$ & $\varepsilon r, q$ & Ir & $r r, 1$ & 9 & الإجمالى \\
\hline
\end{tabular}

• زمن عرض القضايا البيئية يكون اقل من ه دقائق وهذازمن غير كافى لتناول القضايا

البيئية

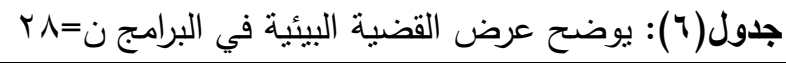

\begin{tabular}{|c|c|c|c|c|c|c|c|c|}
\hline \multicolumn{2}{|c|}{ الإجمالي } & \multicolumn{2}{|c|}{ شباب المستقبل } & \multicolumn{2}{|c|}{ والعاصمة } & \multicolumn{2}{|c|}{ مع الناس } & \\
\hline $1 \ldots$ & $\overline{r \Lambda}$ & ro,. & $\bar{V}$ & $\varepsilon Y, q$ & IT & $\overline{r, I}$ & 9 & تلخيص القضية \\
\hline $1 \varepsilon, \Gamma$ & $\varepsilon$ & $r, \tau$ & $T$ & $v, 1$ & T & $r, \tau$ & $T$ & طرح حلول وبدائل \\
\hline$\Lambda 0, V$ & $T \xi$ & $Y_{1, \xi}$ & 7 & $\Gamma 0, \nu$ & 1. & $r \wedge, 7$ & $\lambda$ & عرض دون حل \\
\hline$r q, r$ & 11 & $1 \leqslant, \Gamma$ & $\varepsilon$ & $1 \leqslant, \Gamma$ & $\varepsilon$ & $1 \cdot, v$ & $\mu$ & نقض القضية \\
\hline$r \wedge, T$ & $\Lambda$ & $1 v, 9$ & 0 & $r, \tau$ & 1 & $\mathrm{~V}, 1$ & $r$ & الحث على المشاركة \\
\hline
\end{tabular}

• يتم عرض القضية بدون تقديم اى حلول الدراسة الميدانيه 
مجلة العلوم البيئية

معهد الدراسات والبحوث البيئية - جامعة عين شمس له

جدول(V): يوضح لماذا نتاهد عينة الدراسة البرامج الخدمية التي تذاع على قناة القاهرة

\begin{tabular}{|c|c|c|c|c|c|c|c|c|c|}
\hline \multirow{2}{*}{ الترتيب } & \multicolumn{2}{|c|}{ الإجمالي } & \multicolumn{2}{|c|}{ القليويبةة } & \multicolumn{2}{|c|}{ محافظة } & \multicolumn{2}{|c|}{ محافظة } & \multirow[t]{2}{*}{ المكان } \\
\hline & $\%$ & ك5 & $\%$ & ك & $\%$ & s & $\%$ & ك & \\
\hline 0 & $11, r$ & IV & $7, \vee$ & 1. & $r, V$ & $\varepsilon$ & $r, \cdot$ & $r$ & لآنها موضيوعات \\
\hline 1 & $r_{,}$, & זس & $7,$. & 9 & $7, \cdot$ & 9 & $1,, \cdot$ & 10 & لمعرفة كل ما يتعلق \\
\hline v & $7, \cdot$ & 9 & $\varepsilon, \cdot$ & 7 & & & $r, \cdot$ & $r$ & لأنها تقدام بشكل \\
\hline$\varepsilon$ & 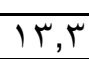 & $r$. & $0, r$ & $\Lambda$ & $7, \mathrm{~V}$ & 1. & $1, r$ & $r$ & لانها متصلة بالحباة \\
\hline$r$ & $I V, r$ & YT & $7, \vee$ & 1. & $\varepsilon, \cdot$ & 7 & $7, \mathrm{~V}$ & 1. & لمعرفة كيف استطيعِ البيئة \\
\hline 7 & $11, r$ & IV & $\varepsilon, V$ & V & $r, v$ & $\varepsilon$ & $\varepsilon$, & 7 & لأنها تقبدة فى الدراسة \\
\hline r & $1 \wedge, \mathrm{V}$ & $r \wedge$ & $v, r$ & 11 & $\varepsilon, \cdot$ & 7 & $v, r$ & 11 & لمعرفة المشكلات في مصر \\
\hline & $1 \ldots$ & 10. & $\varepsilon \cdot, V$ & 71 & YY,. & $r q$ & ru,r & 0. & التإجمالى \\
\hline
\end{tabular}

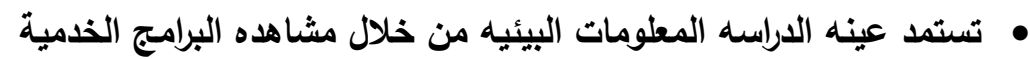

جدول(^): وضح اسباب حرص افراد العينة على مشاهدة هذه البرامج

\begin{tabular}{|c|c|c|c|c|c|c|c|c|c|}
\hline \multirow{2}{*}{ الترتيب } & \multicolumn{2}{|c|}{ الإجمالي } & \multicolumn{2}{|c|}{ القليويبة } & \multicolumn{2}{|c|}{ محافظة } & \multicolumn{2}{|c|}{ محافظة } & \multirow[t]{2}{*}{ المكان } \\
\hline & $\%$ & ك & $\%$ & 5 & $\%$ & 5 & $\%$ & ك & \\
\hline 0 & $T_{,} \cdot$ & $r$ & . & . & . & . & $r, \cdot$ & $r$ & موضوعات شيقة \\
\hline$\varepsilon$ & $\Lambda$, & IT & . & . & $r, r$ & 0 & $\varepsilon, V$ & $\mathrm{~V}$ & أسلوب نقدي جذاب \\
\hline$\mu$ & $r V, \varepsilon$ & $\xi 1$ & $T, \cdot \cdot$ & 11 & $9, \varepsilon$ & $1 \varepsilon$ & $7, \cdot$ & 9 & موعد اذاعته مناسب \\
\hline 1 & $r Y, V$ & $\varepsilon 9$ & $1 \varepsilon, \cdot$ & $Y$ & $\Lambda, \cdot$ & IT & $1 \cdot, \mathrm{V}$ & 17 & تزود بمعلومات بيئية \\
\hline r & $\Gamma \cdot, \cdot$ & «0 & $1 \varepsilon, V$ & rY & $0, r$ & $\wedge$ & $1 \cdot, \cdot$ & 10 & تهتم بعرضئية الإقليم \\
\hline & 1 & 10. & $\varepsilon \cdot, V$ & 71 & ry, & rq & ru, & 0. & الإجمالي \\
\hline
\end{tabular}

• عينه الدراسة تحرص على مشاهدة البرامج الخدمية للتزود بالمعلومات البيئية 
جدول(9): يوضح راي عينة الدراسة في مستوى البرامج الخدمية التي تقدمها القناة الثالثة

\begin{tabular}{|c|c|c|c|c|c|c|c|c|}
\hline \multicolumn{2}{|c|}{ الإجمالي } & \multicolumn{2}{|c|}{ محافظة القليوبية } & \multicolumn{2}{|c|}{ محافظة الجيزة } & \multicolumn{2}{|c|}{ محافظة القاهرة } & \multirow{2}{*}{ المكان } \\
\hline$\%$ & ك & $\%$ & ك5 & $\%$ & ك5 & $\%$ & ك & \\
\hline $17, V$ & Yo & $\varepsilon, V$ & $\bar{V}$ & 7, & $\overline{9}$ & $7,$. & $\overline{9}$ & ررتفع \\
\hline $09, r$ & 19 & $r V, r$ & «1 & 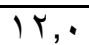 & 11 & $r_{\cdot, \cdot}$ & $r$. & متوسط \\
\hline$T \varepsilon, \cdot$ & 14 & $\Lambda, \vee$ & $1 \pi$ & $\Lambda$, & Ir & $V, r$ & 11 & ضعيف \\
\hline $1 \ldots$ & 10. & $\varepsilon \cdot, V$ & 71 & $r q, \cdot$ & rq & $r \mu, r$ & 0. & الإجمالي \\
\hline
\end{tabular}

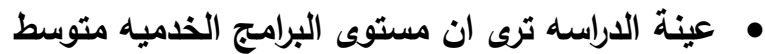

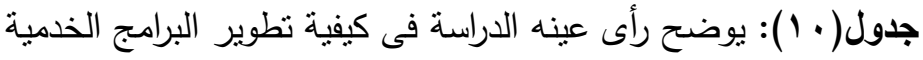

\begin{tabular}{|c|c|c|c|c|c|c|c|c|c|}
\hline \multirow{2}{*}{ الترتيب } & \multicolumn{2}{|c|}{ الإجمالي } & \multicolumn{2}{|c|}{ القليويبة } & \multicolumn{2}{|c|}{ الجيزة } & \multicolumn{2}{|c|}{ محافظة } & \multirow[t]{2}{*}{ المكان } \\
\hline & $\%$ & ك & $\%$ & ك & $\%$ & S & $\%$ & ك & \\
\hline$\mu$ & $1 \wedge, \mathrm{V}$ & $r \wedge$ & $1 \cdot, \cdot$ & 10 & . & · & $\Lambda, \nu$ & r & زيادة عدد البرامجج \\
\hline 0 & $1 \leqslant, V$ & Yr & $\varepsilon, V$ & V & $\varepsilon$, & 7 & $7, \cdot$ & 9 & المخصص زيادة اللقضتابا \\
\hline$\varepsilon$ & 17,7 & ro & $7, \cdot$ & 9 & $0, r$ & $\wedge$ & $0, r$ & $\Lambda$ & نطوير شكل الإخراج \\
\hline 1 & ro,r & rᄉ & r, & IV & $\Lambda, \cdot$ & IT & 7, & 9 & تقديم الفقرات البين فيئية \\
\hline r & $r \leqslant, V$ & rV & $\wedge, \vee$ & $1 \pi$ & $\Lambda, \vee$ & $1 \pi$ & $V, r$ & 11 & بإدخال شقرات البرامدج تخدال \\
\hline & $1 \cdots$ & 10. & $\varepsilon \cdot, V$ & 71 & $r 7, \cdot$ & $r q$ & rT,r & 0. & الإجمالي \\
\hline
\end{tabular}

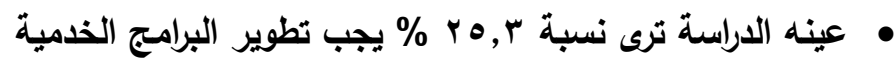

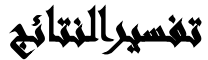

البرامج الحدمية لتى تذاع على شاثنة قناة القاهرة تحتوي على قدر غير كافى من

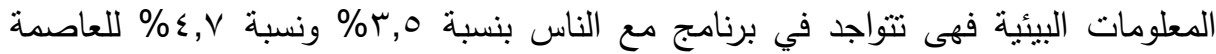

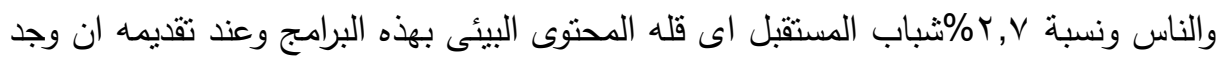
زمن عرض المحتوي لا يتعد ه دقائق ان زمن عرض القضايا البيئية يكون اقل من ه دقائق 


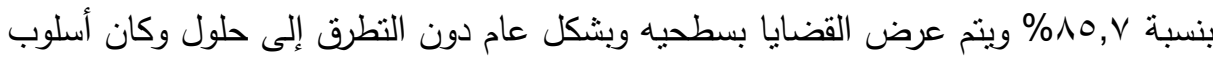
مناقثة القضية سطحي بنسبة 9,0مما يدل علبإغفال العديد من القضايا البيئية الهامة. ويتفق هذا مع رأى عينه الدراسه حيث اكدت ان مستوى البرامج الخدمية التي تقدمها لتهابها القناة الثالثة (القاهره)متوسطة بنسبة r,ه\%\% وهذا يدل على قصور هذه البرامج فى نشر المعلومات البيئيه وان نسبة ro,r من عينة الدراسة ترى انه يجب نطوير البرامج الخدمية حيث ان نسبة ro,r من عينة الدراسة ترى انه يجب تطوير البرامج الخدمية بالاستعانة بمتخصصين في تقديم البرامج ثم تغير شكل البرامج بإدخال فقرات تخدم مجال البيئة بنسبة

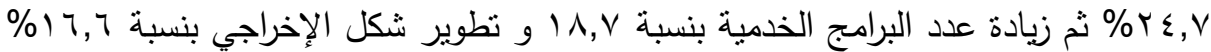
ونسبة V,ـ ا (\% وزيادة الوقت المخصص للقضايا البيئيه المطروحه وعلى هذا يجب تقويم هذه

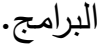

قد أشارت النتائج إلى: ويالربط بين نتائج الدراسه التحليليه والميدانيه واستخدام المعاملات الإحصائية لوجود دلالات بين البيانات :

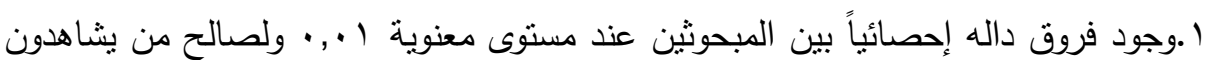
قناة القاهرة فى المعارف البيئية

\begin{tabular}{|c|c|}
\hline مستوى الدلالة & معامل الارتباط \\
\hline.,$\cdot 1$ &., 170 \\
\hline
\end{tabular}

r.وجود فروق داله إحصائيا عند مستوى 1.,., بمعنوية لصالح من بشاهدون البرامج الخدمية بقناة القاهرة بالعشوائيات عن من لا يثاهدونها نحوالمعرفة بالمشكلات البيئيه

\begin{tabular}{|c|c|}
\hline مستوى الدلالة & معامل الارتباط \\
\hline $9, \cdot 1$ & $\cdot, V \cdot r$ \\
\hline
\end{tabular}
المختلفة لصالح المستويات التعليمية العليا نحو معرفة وتحديد المشكلات البيئية

معامل الارتباط

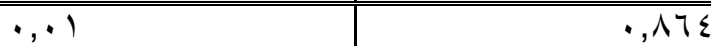


ع..وجود فروق ذات دلاله إحصائيا عند مستوى معنوية ا.,.• وبين المستويات الاقتصادية

\begin{tabular}{|c|c|}
\hline مستوى الدلالة & معامل الارتباط \\
\hline$\cdot, \cdot, 1$ & $\cdot, \vee \backslash 19$ \\
\hline
\end{tabular}

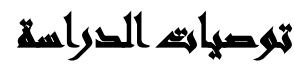

ا. إنشاء برامج بيئيه بقناة القاهرة الإقليمية حيث إن خريطة إرسالها تخلوا من البرامج البيئية

والإهتمام بتقديم المعلومات البيئيه من خلال برامج بيئيه متخصصه تتميز ببارومنريه.

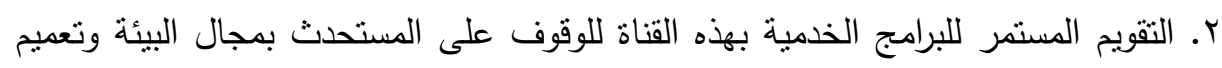
ذلك على البرامج الخدميه بمختلف القنوات الحكوميه والخاصه للعمل على نشر الوعى لئى البيئى. r. العمل على تدريب كوادر إعلاميه تهنت بشئون البيئة بالقطاع الإقليمي وتتعاون مع الأجهزه المعنيه بالبيئه. ء. التعاون المستمر للحصول على المطلومات البيئية الموثقة من أجهزه شئون البيئة ومحطات

$$
\text { الرصد البيئي. }
$$

ه. ربط الرسالة الإعلامية بإحتياجات وإمكانيات وتطلعات الجمهور وخاصه بالمجتمعات

$$
\text { العشوائيه. }
$$

I. الإهتمام بالدور الذي يقوم به القطاع الإقليمي بالهيئه الوطنيه للإعلام في مجال البيئه

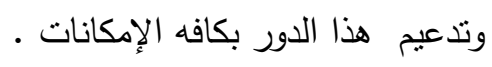

V. الاهتمام بمحتوى الفقرات البيئيه بالبرامج المقدمه والتى يجب التهات ان يقوم على إعدادها

$$
\text { متخصصون في البيئه }
$$




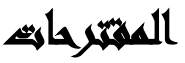

فى ضوء النتائج التى تم التوصل إليها يوصى الباحثون:

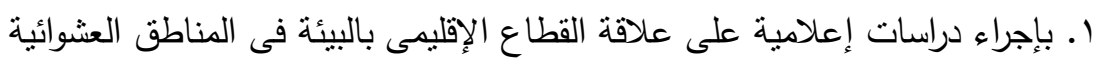
r. تطبيق التصور المقترح لهذة الدراسة على البرامج الخدمية بالهيئة الوطنية للإعلام r. التقويم المستمر للبرامج الخدمية كى تقدم محتوى بيئى يتتاسب مع المستويات المختلفة لئل

\section{zall}

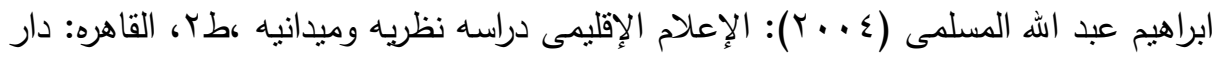

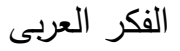

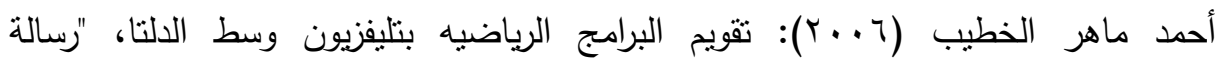
ماجستير ، جامعه طنطا، كلية التربية الرياضيه

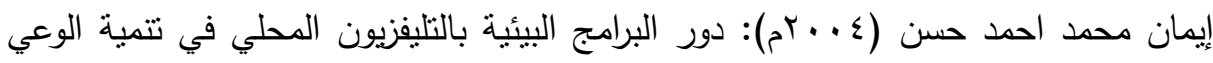

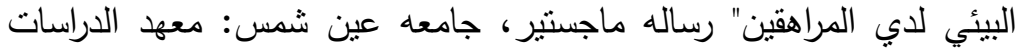
التربويه والبيئيه.

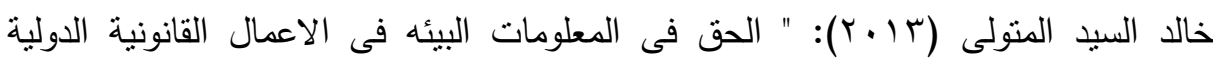
والقوانين البيئية الغربية " جامعه القاهره: سلسله دراسات الديمقراطيه البهات البيئيه.

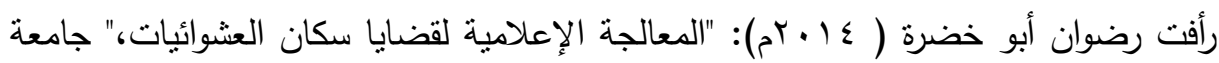
عين شمس: معهد الدراسات العليا للطفولة، قسم الإعلام وثقافة الطفل.

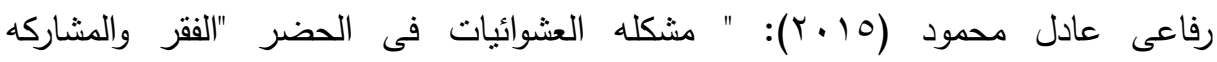

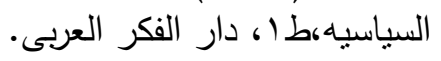

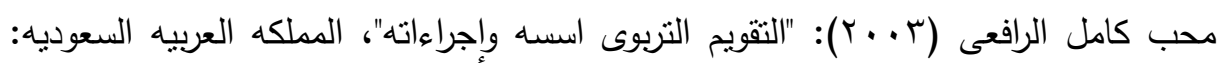

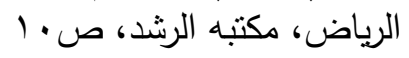

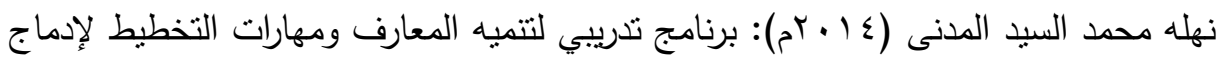

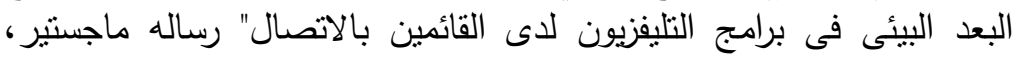
جامعه عين شمس: معهد الدراسات والبحوث البيئية.

$$
\text { المجلد الخامس والأربعون، الجزء الأول، مارس } 19
$$


نهى عادل محمد هريدى (ع ( ب r)): "تغطيه البرامج الحواريه التلبفزيونية المصرية لقضايا

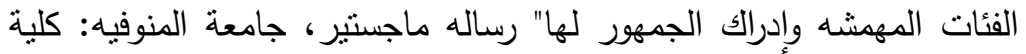

$$
\text { الآداب،غير منشوره. }
$$

Environment: "the journal of high technology management research, volume23, issue1, Elsevier,inc, (2012).

Joel, J.Davis: The Effects of massage framing on Response of Environmental communication Journal Quarterly, v72, n2, 2010.

Keliwheeler (2015): "social media and the effect on youth" Lincoln:university of Nebraska.

Kreg Ritenger, (2010): Television for the Environmentinindia Development communication Repprt, n69.

Mcquails,D (2010): "mass communication theory "6thedition, London: sagepuplication Ltd.

Ronal E.ostmenandJill. Parker: Apublies Environmental informationsources and Evalution of massmedia ,journal Environmental Education, v18, 2009 
مجلة العلوم البيئية

معهد الدراسات والبحوث البيئية - جامعة عين شمس لئس

\title{
EVALUATION OF SERVICE PROGRAMS IN \\ SPREADING ENVIRONMENTAL KNOWLEDGE \\ AMONG AUDIENCE OF CAIRO REGIONAL \\ CHANNEL IN SLUM AREAS
}

\author{
Naglaa, M. M. Ismail ${ }^{(1)}$; Suzan Y. Al-Qelini ${ }^{(2)}$ \\ and Osama, Gabriel ${ }^{(3)}$ \\ 1) Institute of Environmental Studies \& Research, Ain Shams \\ University 2) Faculty of Arts, Ain Shams University 3) Faculty of \\ Educatio, Ain Shams University
}

\begin{abstract}
The aim of the study was to evaluate the service programs for spreading environmental awareness to the viewers of the Cairo Regional Channel affiliated to Al-Mahrousa television network in the informal areas in Greater Cairo.

The researcher used the descriptive approach in both the survey and the content analysis. The field study community included a random sample of (502) single members of some random communities in the Greater Cairo area.

The analytical study included a sample of service programs, including a program with the people, the program of the look at, the program of the city and people broadcast on the channel of Cairo Regional Regional Tools were the study in the design of the questionnaire questionnaire and environmental awareness of the field study.

For the analytical study, a model was designed to analyze the content of the sample programs from the service programs of the Cairo Regional Channel.
\end{abstract}

$$
\text { المجلد الخامس والأربعون، الجزء الأول، مارس } 19
$$


The study found the following results: There were significant differences between the respondents at a significant level of 0.01 for the benefit of those who watched the Cairo channel towards environmental awareness. Therefore, it is possible to say that those who watch the Cairo channel were more aware of the environment.

There are significant differences at the level of 0.01 for the benefit of those who watch the service programs in the channel Cairo Alchatiot for those who do not see them towards the cultural awareness of the environment and it is clear that viewers of service programs are more familiar with environmental information.

There are significant differences at a significant level of 0.01 and the viewers of the Cairo channel in the field of study and the rest of the other channels for the benefit of Cairo channel towards environmental awareness and it is clear that the viewers of Cairo channel receive their environmental information from watching the channel without the rest of the channels.

There are significant differences at the level of significant 0.01 and between different educational levels in favor of higher education levels towards the environmental awareness of these communities and explains that the greater the level of education in the individual the greater the level of knowledge because of the adoption of several different sources to obtain information there are significant differences at the level of 0.01 and between levels The results indicated a significant relationship between the level of environmental awareness and the economic variable, where the higher levels were more environmentally conscious. 